November 2021

\title{
Educators' Use and Views of Simulations as Teaching Tools within a Discipline: The Example of Hospitality and Tourism
}

Cynthia S. Deale

East Carolina University, cindea56@yahoo.com

Stephanie Bae

East Carolina University

Seung-Hyun Lee

East Carolina University

Follow this and additional works at: https://digitalcommons.georgiasouthern.edu/ij-sotl

\section{Recommended Citation}

Deale, Cynthia S.; Bae, Stephanie; and Lee, Seung-Hyun (2021) "Educators' Use and Views of Simulations as Teaching Tools within a Discipline: The Example of Hospitality and Tourism," International Journal for the Scholarship of Teaching and Learning: Vol. 15: No. 2, Article 10.

Available at: https://doi.org/10.20429/ijsotl.2021.150210 


\title{
Educators' Use and Views of Simulations as Teaching Tools within a Discipline: The Example of Hospitality and Tourism
}

\begin{abstract}
This Scholarship of Teaching and Learning study investigated hospitality faculty members' perceptions and use of industry-related simulations in hospitality and tourism education to help the authors understand how simulations are and can be used as educational tools. Using learning engagement theory as a framework, respondents to a survey perceived that simulations help students develop decisionmaking skills, increase problem-solving skills, integrate knowledge from other classes, learn to work with others, and link theory to practice, and noted that simulations are fun to use. A significant positive relationship was found between the number of semesters educators have used simulations and their satisfaction with the simulations. Perceived drawbacks to the use of simulations included that they are costly, time-consuming, too complex, and lack realism and validity. Based on the findings, suggestions are made for improving the use of simulations in hospitality and tourism education, and limitations and ideas for further research are offered.
\end{abstract}

\section{Keywords}

simulations, hospitality educators, perceptions, teaching, learning

\section{Creative Commons License}

c) (i) $(\Theta$

This work is licensed under a Creative Commons Attribution-Noncommercial-No Derivative Works 4.0 License. 
IJ-SoTL, Vol. 15 [2021], No. 2, Art. 10

\title{
Educators' Use and Views of Simulations as Teaching Tools within a Discipline: The Example of Hospitality and Tourism
}

\author{
Cynthia S. Deale, Stephanie Bae, \& Seung-Hyun Lee \\ East Carolina University
}

Received: 26 April 2021;Accepted: 23 June 2021

\begin{abstract}
This Scholarship of Teaching and Learning study investigated hospitality faculty members' perceptions and use of industry-related simulations in hospitality and tourism education to help the authors understand how simulations are and can be used as educational tools. Using learning engagement theory as a framework, respondents to a survey perceived that simulations help students develop decision-making skills, increase problem-solving skills, integrate knowledge from other classes, learn to work with others, and link theory to practice, and noted that simulations are fun to use. A significant positive relationship was found between the number of semesters educators have used simulations and their satisfaction with the simulations. Perceived drawbacks to the use of simulations included that they are costly, time-consuming, too complex, and lack realism and validity. Based on the findings, suggestions are made for improving the use of simulations in hospitality and tourism education, and limitations and ideas for further research are offered.
\end{abstract}

\section{INTRODUCTION}

Simulations have been used for many years as teaching and learning tools in a variety of disciplines, such as engineering (e.g., Saenz \& Cano, 2009), medicine (e.g., Lateef, 2010), management (e.g., Salas, Wildman, \& Piccolo, 2009), and hospitality and tourism management (e.g., Ampountolas, Shaw, \& James, 2019; Feinstein \& Parks, 2002; Pederson \& Pederson, 1993). In hospitality and tourism education, in particular, simulations are used to connect students to various segments of the industry, including lodging, foodservice, and event management (Feinstein \& Parks, 2002; Russell Partnership Technology, 2020), and they are seen as an effective way to consider alternatives in a company or organization without having to implement them in an actual industry setting (Ampountolas et al., 2019). As educational tools, simulations can help students learn about abstract concepts, complex content material, and authentic industry issues through in-depth, interactive learning experiences (Chilcott, 1996; Lateef, 20 I0). In addition, the use of simulations can reduce costs because altering real systems can be expensive and also decrease consumer satisfaction because, as some scholars note, customers do not care to be part of "failed experiments" (Thomas \& Verma, 2003). Yet, although simulations have been used for many years in the hospitality and tourism classroom, questions arise as to the satisfaction with and perceptions of simulations as teaching and learning tools.

While researchers have found using simulations to be worthwhile in hospitality and tourism education, most of the studies about their use are relatively old (e.g., Feinstein \& Parks, 2002; Ferreira, 1997; Thompson \& Verma, 2003) and, although these older studies may still have some relevance, students and the hospitality and tourism industry continue to change. Technology also continues to evolve rapidly, and simulation programs and software used in hospitality and tourism education continue to expand in terms of variety and capacity (Goh \& Sigala, 2020). In addition, previous studies have been limited to students' perceptions of using simulations (Douglas et al., 2008; Martin \& McEvoy, 2003; Pratt \& Hahn, 20I5) even though educators decide if and when to use simulations in their classes. Therefore, the authors found that it would be helpful, as educators, to understand what the current usage and views of various simulations are by faculty members involved in hospitality and tourism education. Thus, the authors of this Scholarship of Teaching and Learning (SoTL) project sought to find out what educators think of simulations and how they use them, in order to improve their own teaching, enhance their students' learning, and share the information with other educators.

\section{LITERATURE REVIEW A Definition of a Simulation}

A simulation can be defined as "an approximate imitation of the operation of a process or system” (Banks et al., 200 I, p. 3), and when students use a model of behavior to gain a better understanding of that behavior, they are doing a simulation (Carleton College, 2020). A simulation is a method of teaching to promote learning about content materials and/or skills, or to assess learning, that is based on an actual situation, and as the simulation proceeds, students respond to the changes within the situation by studying the consequences of their decisions and subsequent actions and predicting future problems/solutions" (Chilcott, 1996, p. 2). In addition, a simulation is a teaching tool that uses a technique for practice and experiential learning that can be implemented in a variety of disciplines (Kent State University, n.d.). It is a technique, not a technology, to replace and amplify real experiences with guided ones, often "immersive" in nature, that call up or replicate significant characteristics of the real world in an interactive manner (Lateef, 20I0). In addition, a simulation does not have to be based on technology, it can be in the form of a game or other classroom activity; however, for the purposes of this study, the term simulation assumes that it is a computer-based tool.

\section{Simulations as Teaching and Learning Tools}

Various simulations have been employed as teaching tools for the instruction of strategic management over the last couple of decades (e.g., Burgess, 1995; Chapmen \& Sorge, 1999; Faria, 1998; Knotts \& Keys, 1997;Wolfe, 1997;Wolfe \& Roge, 1997), and although simulations may not necessarily be used as often as other methods in hospitality and tourism education (Hsu \& Li, 20l7), simulations have been found to be effective teaching and learning tools in the discipline. They are used in hospitality and tourism 
education for practicing teamwork, applying decision-making strategies, improving self-confidence, enhancing communication skills, and comprehending business practices (Ampountolas et al., 2019; Ferreira, 1997; Jennings, 2002; Kesner, 200 I; Knotts \& Keys, 1997; Lateef, 20I0). Educators have also found that simulations motivate students by actively engaging them throughout the learning process by requiring that they apply problem solving and decision-making skills to make the simulation happen (Prado et al., 2020).As a simulation progresses, it is modeling a dynamic system in which the student is directly engaged, and therefore, participating in simulations allows students to take part in systems thinking and can improve their knowledge of systems as well as of social science and/or natural science (Chilcott, 1996).

Typically, to use a simulation in a class related to management, students are placed into groups and may take on specific roles in the industry such as that of Chief Executive Officer (CEO) or Vice President (Salas et al., 2009). Then, each group is supposed to lead a company and compete with other organizations in a particular segment of the industry, making weekly decisions and facing realistic business situations (Thomas, 1998). As noted, the student team's work involves examining the internal and external environment of a business, discovering business opportunities, studying important markets, determining choices regarding products and services, creating a competitive environment for operations, distributing resources thoughtfully, and building a balance sheet and a profit and loss statement (Okumus \& Wong, 2004; Salas et al., 2009; Thomas, 1998).

However, while the method allows students to learn about operating a firm and helps them to develop self-awareness, the simulation may not actually reflect the real business world, and the simulation itself may cost a considerable amount of money (Thomas, 1998; Okumus \& Wong, 2004). In addition, researchers have found that while simulations are well accepted by students as learning tools, their use does not always help "to generate existing knowledge or to produce new knowledge" (Ampountolas et al., 2019, p. 135). Furthermore, as Okumus and Wong (2004, p. 24) observed, "This method may be viewed by students as fun and may not be taken seriously." Thus, to effectively use simulations, instructors need to carefully consider their use and identify how to use them effectively within their courses (Edelheim \& Ueda, 2007).

\section{The Framework of Learning Engagement}

Scholars of engagement theory have proposed that students must be significantly engaged in learning experiences via their work with others and their participation in meaningful activities (Kearsley \& Schneiderman, 1998). The foundation of engagement theory is the implementation of successful collaborative teams that complete projects that are of value to someone outside the educational environment. Pioneers in engagement theory, Kearsley and Shneiderman (e.g., Kearsley \& Schneiderman, 1998; Shneiderman, 1998, 1998a; Shneiderman et al., 1995) noted that because technological applications have been shown to facilitate learning in unique ways, engagement theory is a viable conceptual framework for technology-based teaching and learning.

Engagement theory revolves around the following three key parts: relating, creating, and donating. These infer that the learning activities take place in collaborative groups or teams, are project-based, and have an authentic focus (Kearsley \& Shneiderman, 1998).
Researchers who completed an experiment that supported the theory include Miliszewska and Horwood (2006) who designed and conducted an experiment to demonstrate how engagement theory works. They developed and implemented an online project and found that students were fully engaged, even though they were in different countries and locations and developed problem-solving skills, which enhanced the learning environment. In another study, Fink (2013) also supported the theory that technology promotes engagement in learning that might be difficult to achieve otherwise. Given the importance of practical applications in learning in the discipline of hospitality and tourism, this SoTL study applied engagement theory as its framework for the study of educators' perceptions of the use of simulations in hospitality and tourism education.

\section{PURPOSE}

As noted, research studies have been conducted about the use of simulations in a variety of disciplines, including that of hospitality and tourism education, but many studies are over a decade old (e.g., Edelheim \& Ueda, 2007; Feinstein \& Parks, 2002; Okumus \& Wong, 2004; Thomas \& Verma, 2003), and students' life experiences differ from a decade ago. This is in part due to advances in technology, artificial intelligence, and digitalization. Ten years ago, college students, of traditional college age, were primarily millennials (Gen Y), born between I98I and 1996, who grew up during the ascent of the internet.Whereas college students of traditional age today (primarily Gen Z), were born during or after 1997 and grew up with technology all around them, including social media (Bond, 2020).Therefore, current college students differ from those of past generations and their use of teaching and learning tools such as simulations may differ from those of previous generations.

In addition, most research has focused on students' perceptions of simulations, concentrating on aspects such as their usefulness (Douglas et al., 2008), student satisfaction (Pratt \& Hahn, 20I5; Martin \& McEvoy, 2003), and overall student experience (Martin \& McEvoy, 2003). However, there is a lack of research about simulations from an instructor's perspective, which is an important one, given that educators decide if and when to use simulations in their classes. Questions about faculty members' perceptions of their current and future use remain unanswered, such as, what do hospitality and tourism educators think now about the use of simulations with regard to teaching and learning, and specifically engagement, and what are their current views about simulations as teaching tools?

Therefore, the purpose of this SoTL study was to ascertain the current application and perceptions of simulations by faculty members in hospitality and tourism education. Using learning engagement theory as a framework, this study was guided by the following research questions:

\section{What kinds of simulations are offered to stu- dents?}

What do faculty members believe are the benefits and drawbacks of using simulations for students?

What roles do educators perceive simulations play as part of their students' education, and specifically with regard to their engagement with learning? 


\section{What suggestions do faculty members have for the effective use of simulations in hospi- tality and tourism education?}

\section{METHODOLOGY}

This project was conducted as a SoTL study. SoTL has been defined as the systematic investigation of teaching and learning, applying recognized or proven standards of scholarship, to understand how beliefs, behaviors, attitudes, and values about teaching can enhance learning and/or create a more authentic understanding of learning, giving rise to outcomes that are publicly shared (Potter \& Kustra, 2013; Simmons \& Marquis, 2017). The goal of SoTL can be described very simply as authentic investigations into improving student learning and enhancing educational quality (Kreber, 2007; Poole \& Simmons, 2013). Furthermore, similar to other types of scholarship, SoTL requires thoughtful, purposeful methods and methodologies derived from diverse fields, disciplines, and viewpoints (Chick, 20I4).With that focus at the heart of this project, this SoTL study investigated educators' use and views of simulations as teaching tools in the hospitality and tourism discipline.

This SoTL study employed the survey method as it allowed the researchers to access a sample in a relatively easy manner and attain information in an anonymous way. The survey was built using a Qualtrics online survey website to reach hospitality and tourism educators regardless of their physical location. This study was comprised of both quantitative and qualitative items, focusing on the use and perception of simulations in hospitality and tourism education. The quantitative items supplied numeric data, while the qualitative items enabled the authors to acquire valuable additional data about the study's objectives.

The survey questions about the benefits and drawbacks of simulations were adopted from previous literature in hospitality and tourism education (Edelheim \& Ueda, 2007; Fawcett \& Lockwood, 2000; Okumus \& Wong, 2004) and business education (Gopinath \& Sawyer, 1999; Jennings, 2002), because of the similarities between these two disciplines. The items discussing the benefits of the simulations are from the work by Edelheim and Ueda (2007), Fawcett and Lockwood (2000), Gopinath and Sawyer (1999), Jennings (2002), and Okumus and Wong (2004), whereas the drawbacks of the simulations are from the work by Edelheim and Ueda (2007) and Okumus and Wong (2004). The questions used a five-point Likert scale to ask respondents to rate the degree of agreement with the survey items, that ranged from I (strongly disagree) to 5 (strongly agree). Educators were also asked to provide any additional benefits and/or drawbacks that they observed while using the simulation.

A list of hospitality and tourism simulations was generated by the authors. The list was compiled using the results of web search engines and other resources, such as discussions with professional association members and partners. In addition to the list of simulations offered on the survey, the authors provided the respondents with the opportunity to type in any additional simulations. Thus, they could provide the title(s) of the simulation(s) they had used if the simulation was not included on the list. In addition, a few open-ended questions were used to gain further insights into the hospitality and tourism educators' views about the topic (e.g., what new simulations would you like to see developed?). The latter part of the survey asked for demographic information.
After the Institutional Review Board approved the proposal for the study, a pilot survey was conducted with 21 hospitality and tourism educators. The pilot survey indicated that editing was necessary, and questions had to be rearranged in order to enhance the flow and readability of the survey. The questionnaire was revised based on their feedback before collecting the data. A convenience sampling method was used due to time and resource constraints. An invitation to participate in the study and a survey link were sent via email to faculty members on a global listserv of educators that shares and discusses information and issues related to hospitality and tourism. The listserv is an email distribution list that connects those involved in the hospitality and tourism education community. It was started and is still managed by the School of Travel Industry Management at the University of Hawaii, Manoa. It includes over 2,900 subscribers from more than 60 countries (University of Hawaii at Manoa, 2018). As members of the list-serv, hospitality and tourism educators and doctoral students, receive emails from other members informing them about conferences, calls for papers, and other information pertaining to the hospitality and tourism discipline. The researchers subscribed to the listserv, as members, in the fall of 2019 when the data were collected. After the initial invitation was sent via email, a reminder email was sent to all members to follow up on the prior invitation to participate in the study. The data collection process lasted two weeks. Researchers reviewed the data and removed surveys that were missing major items. For the quantitative responses, descriptive analyses and regression analysis were used via SPSS 26. Means and standard deviations of benefits and drawbacks were run to study educators' perceptions of simulations, and regression analysis was used to determine if there was a relationship between the length of the simulation use and satisfaction with the simulations.

To analyze the qualitative comments, content analysis was carried out according to methods suggested by scholars in qualitative methods (Berg, 2004; Malterud, 20I2). In this project, thematic analysis was applied, grounded in the technique used by Braun and Clark (2006). A researcher and two graduate students coded the data separately. First, the comments were read as a whole and then for the second phase, the comments were read a second time and were coded by having labels attached to interesting and frequently mentioned text. Next, the codes were reviewed for themes and then the themes were described and named (Braun \& Clarke, 2006). Finally, coders compared the themes that they acquired through the data as a form of cross-validation of the final clarification of the comments, as recommended by scholars of the content analysis method (Berg, 2004; Malterud, 20I2; Neuendorf, 2002).

\section{RESULTS Demographics}

For this study, 167 surveys were collected from hospitality and tourism faculty members; however, only 122 surveys were used for analysis, as 45 incomplete surveys were removed. The sample consisted of more males $(52.7 \%)$ than females (47.3\%), more assistant professors $(28.6 \%)$ and associate professors $(28.6 \%)$ than other types of faculty members, and about half of the respondents were tenured (48.6\%). Their ages ranged from 26 to 77 years, with an average age of 47 years (see Table I). Their institutions were primarily categorized as four-year public institutions (64.8\%), located in urban areas (64.4\%), and most of the programs required an internship or externship (86.7\%). Respondents' programs were 
housed most often in a freestanding college or school (42.9\%), followed by a business college or school (34.3\%), or a human ecology or human sciences college or school (12.4\%). Approximately 87 percent of the participants reported that they had worked in the hospitality industry prior to joining academia (86.6\%). Their work varied and included the following positions: revenue manager, marketing specialist, hotel general manager, restaurant manager, club manager, executive chef, consultant, and catering manager. Lastly, the geographic locations of respondents were diverse, including respondents from six continents. Out of 91 respondents who reported their current location, over half of the respondents (53\%) were from the United States, followed by the Philippines (14\%), Switzerland (7\%), France (4\%), Australia (3\%), and Spain (3\%). Other countries mentioned were Italy, Malaysia, Canada, Nigeria, Brazil, Kenya, Turkey, and Japan.

Over sixty percent $(64.8 \%)$ of the participants reported that they had used a simulation in a class that they taught. Faculty members reported using several types of simulations. The most

\begin{tabular}{|c|c|c|}
\hline & Frequency & Percent \\
\hline \multicolumn{3}{|l|}{ Sex } \\
\hline Male & 59 & 52.7 \\
\hline Female & 53 & 47.3 \\
\hline \multicolumn{3}{|l|}{ Faculty rank } \\
\hline Assistant Professor & 32 & 28.6 \\
\hline Associate Professor & 32 & 28.6 \\
\hline Professor & 31 & 27.7 \\
\hline Teaching Instructor & 10 & 8.9 \\
\hline Adjunct & 3 & 2.7 \\
\hline Graduate student & 4 & 3.6 \\
\hline \multicolumn{3}{|l|}{ Administrative appointment } \\
\hline Yes & 42 & 38.2 \\
\hline No & 68 & 61.8 \\
\hline \multicolumn{3}{|l|}{ Tenure status } \\
\hline Tenured & 54 & 48.6 \\
\hline Tenure-track & 14 & 12.6 \\
\hline Does not apply & 43 & 38.7 \\
\hline \multicolumn{3}{|l|}{ Education } \\
\hline Doctorate & 74 & 67.3 \\
\hline Master's & 36 & 32.7 \\
\hline \multicolumn{3}{|l|}{ Work experience } \\
\hline Yes & 97 & 86.6 \\
\hline No & 15 & 13.4 \\
\hline \multicolumn{3}{|l|}{ Classification of institution } \\
\hline Public, 4-year & 68 & 64.8 \\
\hline Private, 4-year & 22 & 21.0 \\
\hline Public, 2-year & 7 & 6.7 \\
\hline Private, 2-year & 2 & 1.9 \\
\hline Public, 3-year & 6 & 5.7 \\
\hline \multicolumn{3}{|l|}{ Location of institution } \\
\hline Urban & 67 & 64.4 \\
\hline Rural & 37 & 35.6 \\
\hline \multicolumn{3}{|l|}{ Hospitality education program housed } \\
\hline Freestanding college/school & 45 & 42.9 \\
\hline Within a business college/school & 36 & 34.3 \\
\hline $\begin{array}{l}\text { Within a human ecology or human } \\
\text { sciences college/school }\end{array}$ & 13 & 12.4 \\
\hline Within an agricultural college/school & 4 & 3.8 \\
\hline Other & 7 & 6.7 \\
\hline \multicolumn{3}{|l|}{ Externship or internship } \\
\hline Yes & 91 & 86.7 \\
\hline No & 14 & 13.3 \\
\hline
\end{tabular}

frequently used simulations were Operations - Front Office (by Knowledge Matters) (I I\%) and Food \& Beverage - Restaurant Basics (by Knowledge Matters) (I I\%), followed by HOTS (by RP Tech/Russell) (10\%), Revenue Management - Basic (by Knowledge Matters) (7\%), and Operations - Housekeeping (by Knowledge Matters) (6\%). Other simulations reported by the respondents included: HotelSIM (by RPTech/Russell), Airline Management Simulation (by AirwaySim and AirlineSim), InnRoad (by InnRoad, Inc.), and General Manager (by Knowledge Matters). It should be noted that the respondents could choose more than one simulation because multiple simulations can be used in different courses (see Table 2).

\section{Perceptions of Simulations}

The faculty members surveyed indicated that there are several benefits to students that occur through the use of simulations. They believed that by using simulations students develop decision-making skills $(m=4.63)$, increase problem-solving skills $(m=4.56)$, integrate knowledge from other classes $(m=4.39)$, and learn to work with others $(m=4.13)$. Moreover, while they believed that simulations are interesting and fun $(m=4.55)$, they felt that simulations also link theory to practice $(m=4.27)$ (see Table 3). These findings were in line with the theory of learning engagement that encompasses, relating, creating, and donating (Kearsey \& Shneiderman, 1998). Overall, faculty members were satisfied with the simulations they have used $(m=4.1 \mathrm{I})$. Interestingly, a significant positive relationship was found between the number of semesters faculty members have used simulations and their satisfaction with the simulations $(\beta=.266, p=.027)$. The longer educators used a simulation, the more they were satisfied with the simulation, indicating that it takes time for faculty members to fully appreciate the benefits of simulations.

In their qualitative comments, the educators mentioned additional benefits (and note that they could mention more than one

\begin{tabular}{|c|c|c|}
\hline Simulation Name & Frequency & $\%$ \\
\hline Operations - Front Office & 17 & $11 \%$ \\
\hline F\&B - Restaurant Basics & 17 & $11 \%$ \\
\hline HOTS & 16 & $10 \%$ \\
\hline Revenue Mgt - Basic & II & $7 \%$ \\
\hline Operations - Housekeeping & 10 & $6 \%$ \\
\hline Operations - Engineering & 10 & $6 \%$ \\
\hline HotelSIM & 9 & $6 \%$ \\
\hline Guest Services - Social media & 8 & $5 \%$ \\
\hline F\&B - Banquets & 7 & $4 \%$ \\
\hline F\&B Manager - Hotel Restaurant & 7 & $4 \%$ \\
\hline GM Limited Services & 6 & $4 \%$ \\
\hline RevSIM & 6 & $4 \%$ \\
\hline Sales \& Marketing - Group Sales & 5 & $3 \%$ \\
\hline GM Full Service & 5 & $3 \%$ \\
\hline Others & 5 & $3 \%$ \\
\hline ProSIM & 4 & $3 \%$ \\
\hline General business & 4 & $3 \%$ \\
\hline Revenue Mgt - Advanced & 3 & $2 \%$ \\
\hline InnRoad/Opera & 2 & $1 \%$ \\
\hline Destination Management by Topsim & 2 & $1 \%$ \\
\hline Hospitality Accounting & $\mathrm{I}$ & $1 \%$ \\
\hline Hospitality Business Acumen & $\mathrm{I}$ & $1 \%$ \\
\hline F\&BSIM & $\mathrm{I}$ & $1 \%$ \\
\hline Total & 157 & $100 \%$ \\
\hline \multicolumn{3}{|c|}{ Note:The respondents were asked to check all that apply } \\
\hline
\end{tabular}


in the answer). The most commonly identified benefits were that simulations link theory to practice $(n=67)$, followed by their use in online learning environments $(n=5 \mathrm{I})$. For example, one educator stated the following," It is a great activity to link in-class work with a simulated practical experience." While another noted that, "It is great in the online environment where you might not provide any other hands-on work." Others noted how simulations provide hands-on learning opportunities $(n=42)$ and offer ways to apply student learning and a risk-free environment $(n=23)$. Representative comments included the following:

Provides some sort of "hands-on" aspect for the course when it is not possible to work in or shadow a real hotel or restaurant operation as part of the course.

Provides a safe, risk free environment for students to practice/apply their competencies and skills set. Provides a suitable active learning environment and encourages peer-learning and collegiality.

Several of the comments focused on the teamwork aspects of simulations $(n=42)$. The hospitality industry promotes working in teams; thus, it was not surprising that the educators stated that working with other people in a team setting, and also working with other teams in a competitive environment, help to prepare students for the industry. Representative comments included the following:

I assign my students into their groups, so it forces them to work with people that they're not familiar with which sometimes leads to personality conflicts, which is typically what they'll experience in the workplace. I think in the safe space of college is a good place to develop conflict resolution skills that they'll certainly utilize in life.

...it fosters teamwork among students...

...promotes collaborative learning between the group and enhances competitive behaviors.

In addition, faculty members recommended the use of simulations in courses addressing several areas of the hospitality and tourism industry. These included lodging $(68.9 \%)$, food and beverage operations (63.1\%), meetings and events (51.6\%), tourism (49.2\%), attractions (37.7\%), and transportation (35.2\%). Other respondents mentioned casinos, cruises, and hospitality human resources.

Faculty members also identified several drawbacks involved in the use of simulations. They believed that simulations are costly

\begin{tabular}{|l|c|c|}
\hline \multicolumn{3}{|l|}{ Table 3. Benefits of Simulations for Students (n= I2) } \\
\hline & Mean & Std. Deviation \\
\hline Develop decision-making skills & 4.63 & 0.75 \\
\hline Increase problem-solving skills & 4.56 & 0.76 \\
\hline Interesting/Fun & 4.55 & 0.81 \\
\hline Integrate knowledge from other classes & 4.39 & 0.79 \\
\hline Link theory to practice & 4.27 & 0.99 \\
\hline Learn to work with others & 4.13 & $\mathrm{I} .15$ \\
\hline Develop quantitative skills & 4.05 & $\mathrm{I} .06$ \\
\hline Enhance communication skills & 3.85 & $\mathrm{I} .20$ \\
\hline Learn about self as a manager & 3.83 & $\mathrm{I} .22$ \\
\hline Develop computing skills & 3.66 & $\mathrm{I} .25$ \\
\hline Clarify career interests & 3.36 & $\mathrm{I} .30$ \\
\hline Note: a 5- point Likert scale was used. & \multicolumn{2}{|l}{} \\
\hline
\end{tabular}

to purchase $(m=3.37)$, time-consuming $(m=2.99)$, too complex $(m=2.92)$, and lack realism $(m=2.92)$ (see Table 4$)$. In their qualitative comments, several educators mentioned additional drawbacks, such as issues with technology $(n=42)$, that the simulations are rigid or not flexible in terms of how they can be used $(n=\mid 2)$, and that they are stressful for students $(n=10)$. A respondent also shared that,"There's not a lot of support for educators to deliver the simulations. I would like to learn better ways to integrate this activity into my classroom." Examples of other problems encountered with the use of simulations included the following:

- Technical issues and a lack of support for these issues;

- Students believe that they could only work within the given instructions; and

- Sometimes students see simulations as stressful and additional work.

\begin{tabular}{|l|c|c|}
\hline \multicolumn{3}{|c|}{ Table 4. Drawbacks of Simulations for Students (n= I 22) } \\
\hline & Mean & Std. Deviation \\
\hline Costly to purchase & 3.37 & $\mathrm{I} .45$ \\
\hline Time-consuming & 2.99 & 1.31 \\
\hline Too complex & 2.92 & 1.40 \\
\hline Lack of realism & 2.92 & 1.32 \\
\hline Lack of validity & 2.80 & 1.28 \\
\hline Lack of freedom in decisions & 2.67 & 1.25 \\
\hline Note: a 5- point Likert scale was used. & \multicolumn{3}{|l|}{} \\
\hline
\end{tabular}

Furthermore, there were a few comments indicating that respondents felt that a simulation cannot replace instruction and that its use should be carefully planned. For example, one educator commented that "a simulation can be seen as an easy option that doesn't need much preparation, but this is simply not true. For a simulation to work you need to have a very clear scheme of work." Another one noted that, "Some instructors rely too much on it and may not cover enough educational contents making the curriculum weak."

In addition, the respondents were asked to provide insights into the types of simulations they would like to see developed. Seventy comments were provided, and I 3 respondents discussed the need for simulations in the area of meeting and event management. One educator discussed the lack of and the need for "a simulation that allows students to experience every step of the event planning process." Twelve comments focused on the need for simulations addressing tourism management (e.g., tourism planning, travel agency management, tour wholesale, tourism marketing). Five respondents commented that there are simulations focusing on restaurant management and food and beverage management, but there is lack of simulations focusing solely on beverage and/or bar management in general. Additional areas discussed included: hospitality crisis management (3 comments), where the simulation goes over how to deal with diverse threats and disasters affecting the hospitality industry, and general service management (4 comments), discussing customer service recovery and the enhancement of service quality excellence.

Lastly, respondents who had not used any simulations in class were asked for the reasons in an open-ended question; 7I comments were provided. Fourteen educators shared that they had not found a simulation that they thought would work effectively in the class. One noted that "I haven't found a suitable one that will be well blended into my course." Another educa- 
tor shared that he/she/they have not found any simulations that include information at a high enough level that would add value to the class. Ten educators commented that they were concerned about the cost of simulations to students and the university. A few respondents shared that, "cost for students and the school has been a reason that I didn't adopt simulations." In addition, four comments focused on wondering about how the grading of the simulation works. They commented that the scores and/or rankings from the simulation might not always reflect the knowledge students obtained or the effort they put into it. For example, one educator noted that,"While the simulations provide learning opportunities, I could only give credit/no credit for completing the simulation."

\section{DISCUSSION AND IMPLICATIONS Benefits of Simulations}

Overall, respondents held positive views of the use of simulations in hospitality and tourism education. Simulations appear to be popular teaching and learning tools, for well over half of the respondents had used simulations in their classes, and respondents believed that there were several benefits to using simulations in their classes. The top three benefits of using simulations were the following:

- To develop decision-making skills;

- To increase problem-solving skills; and

- They are interesting and/or fun.

The findings that simulations were perceived to be effective for developing decision-making and problem-solving skills were in line with those shared by students in previous studies (e.g.,Ampountolas et al., 2019; Lateef, 20 I0; Prado et al., 2020), as was the finding that their use was interesting and/or fun (Pederson \& Pederson, 1993). The third benefit helps to keep students involved in classroom learning and thus, supports the framework of engaged earning proposed by previous researchers (Kearsley \& Shneiderman, 1998). Hands-on learning was also mentioned as a positive aspect of simulations, which is not surprising, as that has frequently been one of the major goals of simulations (Chilcott, 1996; Prado et al., 2020). Furthermore, it appears that using simulations more frequently increases the faculty member's satisfaction with their use, which makes sense if one thinks about how one becomes more comfortable with using a tool when one uses a tool more often.

\section{Suggestions for Reducing the Drawbacks to the Use of Simulations}

In spite of the many benefits of simulations noted, respondents also mentioned several drawbacks to using simulations in hospitality and tourism education. The top one was that simulations are costly to purchase, and this can be an issue for a number of educational institutions and could potentially be a significant deterrent to their use. The educators' perceptions that simulations cost a lot of money was similar to the view held by students, even several decades ago (Pederson \& Pederson, 1993). Costs of simulations need to be carefully considered and cost may continue to be a factor in their selection and use, as their costs potentially continue to rise in the future. The high cost of textbooks has been a drawback in terms of their use and publishers and institutions have had to work to provide alternative ways to help students access their materials, such as textbook loan programs and scholarships (Lumpkin, 2020). Perhaps similar programs need to be developed to make simulations more financially accessible. In addition, administrators could perhaps consider negotiating the price with the companies to keep the costs down.

Several other drawbacks to simulations were mentioned. These included that simulations are time consuming, instructional support for their use may be lacking, instructors must be very familiar with a simulation before it can be used effectively in a class, that they lack realism and validity, that they feel constrained by the decisions that can be made, that there may be technical difficulties connected with their use, and they may be stressful to use.

To reduce the complaint about simulations being too time-consuming, perhaps there could be ways to shorten the time needed to have students participate effectively in the simulations. The additional drawbacks connect to findings from previous research that indicate that a simulation cannot simply be used as it is purchased and will not be as useful as it could be unless an ongoing process that involves instructor and student evaluations and improvements takes place (Edelheim \&Ueda, 2007). In addition, in previous research (e.g., Douglas et al., 2008), some students perceived that it is more difficult to use a simulation if they are unfamiliar with the software used for the simulation, and this previous finding may also connect to the additional drawbacks found by instructors in this study.

One idea to help eliminate some of the drawbacks regarding the use of simulations, including the time spent, their complexity, and high cost, could be to develop mini-simulations that are less in-depth, or shorter, and simpler to use, and that could perhaps be used in module form, and therefore, could be less costly. Perhaps after instructors complete training about how to use a simulation, either in-person or online, they and their students could complete mini-simulations first prior to working on full-length ones. Possibly having a short-term simulation first and then graduating to a longer one would enhance both student and instructor success regarding their experiences with the process and content of the simulation. Since overall perceptions of simulations were positive, developing ways to eliminate drawbacks could potentially make them even more effective and appealing teaching and learning tools.

Furthermore, perhaps to help to ameliorate some of the drawbacks, those who create and promote simulations could involve instructors more fully in the design and pilot phase of a simulation, in particular this could help to reduce stress and enhance validity and perhaps feelings of control with regard to the use of simulations. Once a simulation is launched, it could be wise to provide ongoing training programs for faculty members, engage faculty members in online focus groups (and in-person focus groups at conferences) and workshops to hear their concerns and solicit their input, and connect industry partners with simulation designers and educators to ensure that they are realistic. In addition, possibly support groups for both students and instructors would be meaningful.

Although many simulations are presented at conferences and those working for the companies providing the simulations often try to engage faculty members in discussions about their use, it was interesting that these kinds of comments were made on the survey. Perhaps that was due to some not uncommon realities of teaching, such as being the only instructor at an institution using a particular simulation and needing help with its use during a class, while it is in use.Thus, ongoing, extensive systems of support for instructors and their students are important. 
Not surprisingly, hospitality and tourism educators emphasized the importance of learning about and understanding a simulation, and of becoming well-versed in it before using it in class. Several respondents commented that using simulations does not replace the curriculum; rather, it weakens the quality of instruction if faculty members rely too much on simulations and do not teach educational content. A few educators shared that they had observed or experienced the downfall of not fully understanding the simulation and/or relying too much on the simulation that they felt did not have proper educational content. Therefore, faculty members wishing to use simulations in their class(es) should take time to learn how to use the simulation thoroughly and become well-versed in it so that they can answer any questions students might have and provide students with helpful advice and guidance. In addition, educators should develop a set of relevant exercises and activities for students to complete alongside the simulations, and those developing the simulations can help to provide ideas for learning exercises and activities, in order to provide meaningful learning experiences, and to link theory and practice in hospitality and tourism education.

As far as a potential lack of realism and/or validity, this might also relate to the recommendation to further involve faculty members in the design process. In fact, it might be helpful to ensure that industry professionals, faculty members, and students communicate with each other and work together with the simulation designers to critically consider issues about the design and implementation of the simulations to help ensure that they are realistic and plausible. Perhaps having these stakeholder groups work together to explore additional information about current real-world, authentic hospitality and /or tourism business scenarios, having ongoing discussions, and providing updates could help to provide more realism.

Hearing that there can be technical difficulties was not a surprise, but perhaps there are ways to help ameliorate those problems. One might say that getting new equipment is the answer, but as one knows, that is not an easy solution in higher education. This drawback might at times be related to the complexity, so ensuring that the simulations offer the learning experience desired, but are as simple as possible might be a strategy to consider. In addition, making sure that the simulation designers, educators, students, and technical specialists work together to craft userfriendly, technically compatible, and operational simulations is imperative.

Some comments provided by respondents noted that simulations can be stressful for students and that feeling probably can be alleviated, at least to some extent. In a situation where using a simulation is stressful for students, one would guess that they are also stressful for the instructor; thus, perhaps some suggestions to make their use less stressful for everyone would be welcomed. One simple strategy is to think about the entire process of using the simulation, including how to set it up and plan for its use, how to conduct it, and how to debrief it once it is completed.

\section{RECOMMENDATIONS FOR USING SIMULATIONS \\ Planning and Preparation}

Several recommendations for the use of simulations in teaching and learning emerged through this study, including suggestions for planning, and preparing to use the simulations. Prior to using a simulation, an instructor would be wise to plan and prepare to use it in a careful manner. One helpful and perhaps not always obvious objective is to try to get the students excited about using the simulation by showing them examples of how others have enjoyed using the simulation to learn about concepts and acquire skills. Providing the students with current information about the topic of the simulation occurring in the real world could help to stimulate student interest. Doing this could also help students understand the desired learning outcomes. In addition, sharing how the simulation has been used by others to pique their interest, and anticipating and planning ahead for potential problems and issues may help direct the students as they begin their journey with the simulation. Overall, as noted by earlier work, it would be wise to provide the students with a thoughtful, useful introduction to the simulation, and a user-friendly learning guide (Chilcott, 1996).

\section{Using Leaders and Teams}

An instructor might also consider having student simulation leaders in a class to help alleviate stress and increase the effectiveness of teaching and learning with simulations. The student leaders could be identified by the instructor, or perhaps students could self-identify themselves as simulation leaders, as those who are particularly adept at using technology, and willing to become peer-facilitators regarding the use of the simulation. Student leaders could possibly be students who have completed the simulation in a previous class and could then serve as teaching assistants, and they might be able to do so by completing an independent study. Alternatively, there might be students in the current class who are willing to serve in a leadership capacity because they are particularly capable with tools such as the simulation.

As noted previously, simulations are typically conducted in student teams, and helping the students to work well together might be a useful strategy to help decrease stress and increase the successful use of the simulation. Therefore, prior to beginning the simulation, instructors would do well to spend time preparing not only how to use the simulation, but also preparing for how to have students work well in teams. In terms of creating teams, there are several options, including having the instructor select the teams, having students select their team members, or randomly assigning students to teams. It has been suggested by researchers that having the instructor select the team members is most effective in this case because if students select team members themselves, then strong students tend to work together, "leaving the weaker ones to shift for themselves, which works to no one's benefit" (Oakley et al., 2004; p. II).

A suggestion to instructors to help them with the task of team creation is to have every student complete an introductory assignment about who they are and what their strengths are in relation to the course and the simulation, specifically. Instructors should also be sure to discuss the following with their students: team policies, student expectations, team contracts, progress reports, identifying how to deal with team members who are not fully participating, and peer evaluations (Jassawalla et al., 2009; Oakley, et al., 2004). These recommendations apply whether teams are face-to-face or virtual, for in reality almost all teams in today's world are virtual to some extent (Martins et al., 2004).

\section{Discussing and Debriefing}

During the simulation, it may be helpful to have ongoing discussions about the topic in person or online, according to one's 
course format or teaching style. It would also be wise to observe the simulation process carefully and to communicate with students during the simulation to ensure that they are on track to achieve the learning objectives and to help reduce any stress that they might feel. Knowing that an instructor is invested in their learning and prepared to help guide them, even when using a tool such as a simulation that is new to them, can help to provide students with a more positive learning experience.

Furthermore, debriefing the simulation once it is over is important. As with other role-playing exercises, students may need a chance to review, question, and clarify what they learned through the experience (Chilcott, 1996). This part of the process can be especially important because students may learn much more than what the learning objectives specified, but they may need to express their own views about what they learned and to communicate with each other and with the instructor to feel more positive about their experience with the simulation.

\section{CONCLUSIONS, LIMITATIONS, AND FURTHER RESEARCH}

The findings of this study have practical implications and emphasize the usefulness of simulations for enhancing student engagement, in keeping with previous research (e.g., Kearsley \& Shneiderman, 1998), in spite of identifying some drawbacks to their use. Although the use of simulations in hospitality and tourism education might be more important than it is in other disciplines because the field focuses on hands-on experiences as well as academic courses, the project has implications for any discipline that uses simulations as teaching tools. While some educators may have used simulations for years, for others their use is new, and the findings and implications of this study may offer some useful information.

Due to the COVID-19 pandemic, many schools moved their classes online in 2020 , and this change may have impacted instructors' and students' satisfaction with their teaching and learning experiences (Smith, 2020; Strauss, 2020). Although many educators hope to return to more on-campus, face-to-face classes in the near future, that may not occur soon and educators may have to continue to be innovative with regard to their teaching, especially in applied fields such as hospitality and tourism. For example, instructors teaching lab classes that typically took place in a kitchen, hotel, restaurant, or other industry-related location, had to come up with creative techniques that would provide students with comparable learning experiences via online classes. Furthermore, although campuses may return to a new normal soon, some teaching tools such as simulations may continue to offer meaningful, experiential learning opportunities for students.

As mentioned earlier, many studies about simulations are over a decade old and the student population has changed; plus, the variety of available simulations has increased tremendously over the past few years, and not much has been explored about instructors' views on their use. Therefore, the findings of this study expand the current knowledge about hospitality and tourism educators' perceptions of simulations, and the benefits and drawbacks of using simulations. These results led to several potentially useful suggestions for the effective use of simulations in hospitality and tourism classes.

However, while this study provided interesting results, it has limitations, such as being limited to one group of faculty members (e.g., members of one listserv), and in terms of the methods used to study about the topic. A larger, more diverse sample and other methods, such as observations and interviews, might have provided different answers. Moreover, this sample only represented 4\% of the population (I 22 respondents out of 2900 members on the listserv). Perhaps the educators who do not use any simulations in their courses felt that they were not invited to participate in the survey. For future studies, it may be interesting to ask why educators decide not to use a simulation. Therefore, generalization should be limited and done with care.

In addition, studying more about engagement theory and student learning outcomes obtained through the use of simulations and investigating students' perceptions and actual use of the tools could be beneficial in future research efforts. Furthermore, it would be helpful look more specifically at perceptions of the various types of simulations available and to compare educators' and students' views regarding the use of industry-related simulations in hospitality and tourism education. In this study, the simulations used by the respondents varied greatly, which made it difficult to compare different simulation programs with regard to respondents' perceptions and satisfaction. Additionally, in reviewing the responses to the question that asked respondents to suggest new simulations that they would like to see developed, the authors noticed that the respondents provided multiple ideas for simulations that already existed (e.g., engineering, lodging, hospitality accounting, revenue management). Faculty members and the firms that create and maintain simulations should work together to educate and learn about the simulations further so that educators can use the simulations that are appropriate for their classes, and that will boost student learning. Still, even with these limitations, this study provides interesting insights into how faculty members perceive simulations that are used as teaching and learning tools, specifically within hospitality and tourism education, but has implications for all educators who may apply simulations as teaching tools to try to enhance their students' experiential learning.

\section{REFERENCES}

Ampountolas, A., Shaw, G., \& James, S. (2019). Active learning to improve self-confidence and decision-making skills through the use of hotel simulation, Journal of Hospitality \& Tourism Education, 3 I (3), I 25-I 38, DOI: I0. I080/I0963758.20 I8. I 487786

Banks, J., Carson, Nelson, B., \& Nicol, D. (200I). Discrete-Event System Simulation. Upper Saddle River, N.J.: Prentice Hall.

Berg, B. L. (2004). Qualitative research methods for the social sciences (5th ed.). Boston, MA: Pearson/Allyn and Bacon.

Bond, C. (2020, August 8). There's a big difference between millennials and generation z. Huff Post, Retrieved from https:// www.huffpost.com

Braun, V. \& Clarke, V. (2006) Using thematic analysis in psychology, Qualitative Research in Psychology, 3:2, 77-I0I. http://doi: I0.1 191/|478088706qp063oa

Burgess, T. (1995). Business gaming: An historical analysis and future perspective. The International Simulation and Gaming Yearbook, 3(2), 64-7.

Carleton College (2020). Teaching with simulations; Pedagogy in action. Science Education Resource Center. Retrieved from https://serc.carleton.edu/sp/library/simulations/index.htmICarleton College (2020a, April 3). Why teach with simulations? Science Education Resource Center. Retrieved from https://serc.carleton.edu/sp/library/simulations/why.html. 
Chapmen, K. \& Sorge, C. (1999). Can a simulation help achieve course objectives? An exploratory study investigating differences among instructional tools. Journal of Education for Business, 74(4), 225-230.

Chick, N. L. (20I4). "Methodologically sound" under the "big tent": An ongoing conversation. nternational Journal for the Scholarship of Teaching and Learning, 8(2). http://dx.doi. org/ I0.20429/ijsotl.20l4.08020 I

Chilcott, J. (1996). Effective Use of Simulations in the Classroom Acton, MA: Creative Learning Exchange. Retrieved from http://static.clexchange.org/ftp/documents/implementation/ IMI996-0I EffectiveUseOfSims.pdf

Douglas, A., Miller, B., Kwansa, F., \& Cummings, P. (2008). Students' perceptions of the usefulness of a virtual simulation in post-secondary hospitality education. Journal of Teaching in Travel \& Tourism, 7(3), I-19.

Edelheim, J., \& Ueda, D. (2007). Effective use of simulations in hospitality management education - a case study. Journal of Hospitality, Leisure, Sport and Tourism Education, 6(I), 18-28.

Faria, A. (1998). Business simulation games: current usage levels - An update. Simulation and Gaming: An International Journal, 29(I), 295-309.

Fawcett, S. L., \& Lockwood, A. (2000). Improving the learning environment for the development of hospitality accountancy skills using computer simulation gaming. Tourism and Hospitality Research, 2(3), 262-276.

Feinstein, A. H., \& Parks, S. J. (2002). The use of simulation in hospitality as an analytic tool and instructional system:A review of the literature. Journal of Hospitality \& Tourism Research, 26(4), 396-421.

Ferreira, R. R. (1997). Measuring student improvement in a hospitality computer simulation. Journal of Hospitality \& Tourism Education, 9(3), 58-6I. doi: I0.1080/ I0963758.1997.10685330

Fink, L. D. (20I3). Creating significant learning experience: An integrated approach to designing college courses. San Francisco, CA: Jossey-Bass.

Goh, E. \& Sigala, M. (2020). Integrating information \& communication technologies (ICT) into classroom instruction:Teaching tips for hospitality educators from a diffusion of innovation approach, Journal of Teaching in Travel \& Tourism, (20)2, I56I65, DOI: 10.1080/153 | 3220.2020.1740636

Gopinath, C., \& Sawyer, J. E. (1999). Exploring the learning from an enterprise simulation. Journal of Management Development, I8(5), 477-489.

Hsu, C. H. C., \& Minglong Li, M. (2017). Effectiveness and usage frequency of learning methods and tools: Perceptions of hospitality students in Hong Kong, Journal of Hospitality \& Tourism Education, 29 (3), I0I-II5, DOI: 10.1080/10963758.2017.1336098

Jassawalla, A., Sashittal, H., \& Malshe, A. (2009). Students' perceptions of social loafing: Its antecedents and consequences in undergraduate business classroom teams. Academy of Management Learning \& Education, 8(I), 42-54.

Jennings, D. (2002). Strategic management: An evaluation of the use of three learning methods, Journal of Management Development, 2 I(9), 655-665.
Kearsey, G. \& Shneiderman, B., (I998). Engagement theory: A framework for technology-based teaching and learning. Educational Technology, 38(5), 20-23.

Kent State University (n.d.). Simulation as a teaching strategy. Center for Teaching and Learning. Retrieved April 19, 2021 from https://www.kent.edu/ctl/simulation-teaching-strategy

Knotts, U. \& Keys, J. ( 1997), Teaching strategic management with a business game, Simulation and Gaming, 28(4), 377-394.

Kreber, C. (2007). What's it really all about? The scholarship of teaching and learning as an

authentic practice. International Journal for the Scholarship of Teaching and Learning, (I). http://dx.doi.org//0.20429/ ijsotl.2007.010103

Lateef, F. (20।0). Simulation-based learning: Just like the real thing. Journal of Emergencies, Trauma, and Shock, 3(4), 348-352. doi: 10.4103/0974-2700.70743

Lumpkin, L. (2020, January 7). Textbooks are pricey. So students are getting creative. The Washington Post. Retrieved February I5, 202I from https://www.washingtonpost.com/local/ education/textbooks-keep-getting-pricier-so-students-aregetting-creative/2020/0 I/ /7/4e l 306b8-30b9-I l ea-9 Ifd82d4e04a3fac_story.html

Malterud, K. (20I2). Systematic text condensation:A strategy for qualitative analysis. Scandinavian Journal of Public Health, 40 ( I), 795-895. doi: I 0. I I77/|4034948|2465030

Malterud, K. (20I2). Systematic text condensation:A strategy for qualitative analysis. Scandinavian Journal of Public Health, 40 ( I), 795-895. doi: I 0. I I77/|4034948I2465030

Martin, D., \& McEvoy, B. (2003). Business simulations: a balanced approach to tourism education. International Journal of Contemporary Hospitality Management, I 5(6), 336-339.

Martins, L., L., Gilson, L. L., \& Maynard, M.T. (2004).Virtual teams: What do we know and where do we go from here? Journal of Management, 30(6),805-835.https://doi.org/10.10 I6/j. jm.2004.05.002

Miliszewska, I., \& Horwood, J. (2006). Engagement theory: A framework for supporting cultural differences in transnational education. ACM SIGCSE Bulletin, 38(I), I-9.

Oakley, B., Felder, R. M., Brent, R., \& Elhaji, I. (2004). Turning student groups into effective teams. Journal of Student-Centered Learning, 2(I),9-34.

Okumus, F. \& Wong, K. (2004). A critical review and evaluation of teaching methods of strategic management in tourism and hospitality schools. Journal of Hospitality \& Tourism Education, I6(2), 22-33.

Pederson, E., \& Pederson, C. (1993). Improving the use of computer simulations in the hospitality curriculum, Hospitality \& Tourism Educator, 5(3), 25-29, DOI: 10.1080/23298758.1993.10685498

Poole, G., \& Simmons, N. (20/3). Contributions of the scholarship of teaching and learning to quality enhancement in Canada. In R. Land \& G. Gordon (Eds.) Enhancing quality in higher education: International perspectives. London: Routledge.

Potter, M.K., \& Kustra, E. (20I I). The relationship between scholarly teaching and SoTL: Models, distinctions, and clarifications. International Journal for the Scholarship of Teaching and Learning, 5(I)(online) http://www.georgiasouthern.edu/ijsotl 
Prado, A.M., Arce, R., Lopez, L.E., Garcia, J., \& Pearson, A.A. (2020). Simulations versus case Studies: Effectively teaching the premises of sustainable development in the classroom. Journal of Business Ethics, I6I(I), 303-327. https://doi. org/I0.1007/s I055I-019-04217-5

Pratt, M. A., \& Hahn, S. (20I5). Effects of simulation on student satisfaction with a capstone course. Journal of Hospitality \& Tourism Education, 27(I), 39-46.

Russell Partnership Technology (2020). Retrieved from https:// www.russellpartnership.com/rp-technology/

Saenz, M. J., \& Cano, J. L. (2009). Experiential learning through simulation games: An empirical study. International Journal of Engineering Education, 25(2), 296-307.

Salas, E.,Wildman, J., \& Piccolo, R. (2009). Using simulation-based training to enhance management education. Academy of Management Learning \& Education,8(4), 559-573.

Shneiderman, B. (1998). Relate-create-donate: An educational philosophy for the cyber-generation, Computers \& Education, $3 I(I), 25-39$.

Shneiderman, B. (1998a). Educational journeys on the web frontier, Educom Review, 33(6), I0-I4.

Shneiderman, B., Borkowski, E. Y., Alavi, M., \& Norman, K. (1998). Emergent patterns of teaching/learning in electronic classrooms. Educational Technology Research and Development, 46(4), 23-42.

Simmons, N., \& Marquis, E. (2017). Promoting and celebrating international SoTL collaborations: An introduction to the special issue. The Canadian Journal for the Scholarship of Teaching \& Learning, 8(2). https://doi.org//0.5206/cjsotl-rca-
cea.2017.2.I

Smith, A.A. (2020, March 13). College faculty in California scramble to adapt as classes move to online instruction. EdSource. Retrieved June 8, 2020 from https://edsource.org/2020/instructors-adapt-online-learning-coronavirus/6255 I 9

Strauss, V. (2020, April 4). These Washington University faculty had rejected online classes - until coronavirus. Here's how they made the switch. The Washington Post. Retrieved April 19, 2020 from https://www.washingtonpost.com/ education/2020/04/04/these-washington-university-faculty-had-rejected-online-classes-until-coronavirus-heres-how-they-made-switch/

Thompson, G., \& Verma, R. (2003). Computer simulation in hospitality teaching, practice, and research. Cornell Hotel and Restaurant Administration Quarterly, 44(2), 85-93.

University of Hawaii at Manoa. (2018). Trinet - Tourism research information network. Retrieved from https://tim.hawaii.edu/ about-values-vision-mission-accreditation/trinet/

Wolfe, J. (1997). The effectiveness of business games in strategic management course work. Simulation and Gaming, 28(4), 360-376.

Wolfe, J., \& Roge, J. (1997). Computerized general games as strategic management learning environments. Simulation and Gaming, 28(4), 423-44I. 